\title{
Visible and Deep-Ultraviolet Raman Spectroscopy as a Tool for Investigation of Structural Changes and Redistribution of Carbon in Ni-Based Ohmic Contacts on Silicon Carbide
}

\author{
Paweł Borowicz, ${ }^{1,2}$ Adrian Kuchuk, ${ }^{3}$ Zbigniew Adamus, ${ }^{4}$ Michał Borysiewicz, ${ }^{5}$ \\ Marek Ekielski, ${ }^{5}$ Eliana Kamińska, ${ }^{5}$ Anna Piotrowska, ${ }^{5}$ and Mariusz Latek ${ }^{1}$ \\ ${ }^{1}$ Department of Characterisation of Nanoelectronic Structures, Institute of Electron Technology, Al. Lotników 32/46, \\ 02-668 Warsaw, Poland \\ ${ }^{2}$ Department of Photochemistry and Spectroscopy, Institute of Physical Chemistry, Polish Academy of Sciences, Kasprzaka 44/52, \\ 01-224 Warsaw, Poland \\ ${ }^{3}$ Diagnostic Center, V. Lashkaryov Institute of Semiconductor Physics, NAS of Ukraine, Pr. Nauky 45, 03028 Kiev, Ukraine \\ ${ }^{4}$ Laboratory of Growth and Physics of Low Dimensional Crystals, Institute of Physics, Polish Academy of Sciences, \\ Al. Lotników 32/46, 02-668 Warsaw, Poland \\ ${ }^{5}$ Department of Micro- and Nanotechnology of Wide Bandgap Semiconductors, Institute of Electron Technology, \\ Al. Lotników 32/46, 02-668 Warsaw, Poland
}

Correspondence should be addressed to Paweł Borowicz, borowicz@ite.waw.pl

Received 8 June 2012; Accepted 27 June 2012

Academic Editors: R. Arenal, W. Bao, M. Mirzaei, and G. Speranza

Copyright (C) 2012 Paweł Borowicz et al. This is an open access article distributed under the Creative Commons Attribution License, which permits unrestricted use, distribution, and reproduction in any medium, provided the original work is properly cited.

\begin{abstract}
Three samples of $4 \mathrm{H}$ polytype of silicon carbide $(4 \mathrm{H}-\mathrm{SiC})$ covered with the following sequence of layers: carbon/ nickel/silicon/nickel/silicon were investigated with micro-Raman spectroscopy. Different thermal treatments of each sample result in differences of carbon layer structure and migration of carbon atoms thorough silicide layer. Two ranges of Raman shift were investigated. The first one is placed between $1000 \mathrm{~cm}^{-1}$ and $2000 \mathrm{~cm}^{-1}$. The main carbon bands $D$ and $G$ are observed in this range. Analysis of the positions of these bands and their intensity ratio enables one to determine the graphitization degree of carbon layer. Additional information about the changes of the carbon layer structure was derived from analysis of $2 D$ band placed around $2700 \mathrm{~cm}^{-1}$. Application of deep ultraviolet excitation delivered information about the structure of carbon layer formed on the free surface of silicides and the distribution of the carbon inside the silicide layer.
\end{abstract}

\section{Introduction}

The following combination of silicon carbide ( $\mathrm{SiC})$ physical properties: wide band gap, high critical electric field, simple method of dielectric layer fabrication (surface oxidation), and large thermal conductivity makes from $\mathrm{SiC}$ very promising material for fabrication high power, high-temperature, and high-frequency electronic devices [1]. The crucial issue in technology of manufacturing SiC-based devices is the capability to form reproducible and reliable ohmic contacts with a low specific contact resistance [2-4].

Formation of ohmic contacts to $\mathrm{SiC}$ is typically manufactured by the deposition of metals followed by hightemperature annealing $\left(\mathrm{HTA}: \sim 1000^{\circ} \mathrm{C}\right)[3-5]$. As was shown previously [4-11] metal/SiC structures are not thermally stable. The following reactions of metals with $\mathrm{SiC}$ are possible:

(i) $\mathrm{SiC}+$ refractory metals $(\mathrm{Ti}, \mathrm{Ta}, \mathrm{W}$, etc. $) \rightarrow \mathrm{HTA} \rightarrow$ carbides (TiC, $\mathrm{TaC}, \mathrm{WC}$, etc.) + silicides ( $\mathrm{TiSix}, \mathrm{TaSi}_{x}$, $\mathrm{WSi}_{x}$, etc.) + ternary phases $\left(\mathrm{TiCSi}_{x}, \mathrm{TaCSi}_{x}, \mathrm{WCSi}_{x}\right.$, etc.);

(ii) $\mathrm{SiC}+$ other metals $(\mathrm{Ni}, \mathrm{Pd}, \mathrm{Pt}$, etc. $) \rightarrow \mathrm{HTA} \rightarrow$ silicides $\left(\mathrm{NiSi}_{x}, \mathrm{PdSi}_{x}, \mathrm{PtSi}_{x}\right)+\mathrm{C}$.

Nickel is the most widely used metal for fabrication of ohmic contacts to n-type $\mathrm{SiC}$ due to the formation of contacts with very low specific contact resistance $\left(\sim 10^{-6} \Omega \mathrm{cm}^{2}\right)$ 
$[2,3]$. In spite of numerous publications and progress in study of interaction between $\mathrm{Ni}$ and $\mathrm{SiC}$, there are still many open questions concerning mechanism of contact formation and its reliability. There are different versions of the ohmic contact formation mechanism:

(i) inhomogeneity of metal-SiC Schottky barrier [12];

(ii) creation of carbon vacancies $[1,13]$ or defect states [10] near the interface region;

(iii) "snowplow effect" of dopants in the SiC substrate [7].

The noncontrolled high temperature reaction between $\mathrm{Ni}$ and $\mathrm{SiC}$, followed by creation of silicides and free carbon atoms, limits the reliability of the Ni-based ohmic contacts. In previous works it was shown [3] that the creation of silicides at metal/SiC interface is not sufficient for ohmic contact formation. The role of carbon species at $\mathrm{SiC} /$ silicide is not fully understood yet. The results obtained by $\mathrm{Lu}$ et al. $[5,14]$ point to crucial role of graphitic structures in the formation of ohmic contacts on $\mathrm{SiC}$ substrate. The type of the starting carbon materials: $\mathrm{C}$ atoms or $\mathrm{C}_{60}$ molecules, has no significant impact on the process.

In our earlier works $[15,16]$ we have investigated various $\mathrm{Ni}$ - and $\mathrm{Ni} / \mathrm{Si}$-based contacts to $\mathrm{SiC}$ and reported on their electrical and structural properties. The characterization was performed by X-ray diffraction (XRD), Rutherford Backscattering Spectrometry (RBS) and Secondary Ion Mass Spectrometry (SIMS). These results have shown that the best ohmic contacts are obtained by using $\mathrm{Si} / \mathrm{Ni} / \mathrm{Si} / \mathrm{Ni}$ metallization scheme with thickness of $\mathrm{Si}$ and $\mathrm{Ni}$ layers optimal for building $\mathrm{Ni}_{2} \mathrm{Si}$ silicide. In this work we focus our attention on the role of carbon phase in the reaction of ohmic contact formation. We have modified our metallization scheme by inserting an additional carbon layer on $\mathrm{SiC}$ surface prior to metallization procedure. To investigate the changes of carbon layer structure under thermal treatment we have chosen Raman spectroscopy, because this technique demonstrated its utility in structural study.

\section{Experimental}

2.1. Samples. The nitrogen-doped n-type $\left(\sim 1 \times 10^{19} \mathrm{~cm}^{-3}\right)$ $4 \mathrm{H}-\mathrm{SiC} 2.97 \mu \mathrm{m}$ thick layers which were grown on $4 \mathrm{H}$ $\mathrm{SiC}$ wafer by chemical vapor deposition (Cree Research Inc.) were used as substrates. The $4 \mathrm{H}-\mathrm{SiC}$ substrates were $8^{\circ}$-off axis, Si-terminated (0001) surfaces. Before deposition of contacts the wafers surface was cleaned according to the procedure described in [15]. Ni, Si, and $\mathrm{C}$ layers were deposited from high purity elemental targets in Ar plasma discharge at the room temperature. Three samples with following sequence of layers $\mathrm{Si}(33 \mathrm{~nm}) / \mathrm{Ni}(30 \mathrm{~nm}) / \mathrm{Si}(33 \mathrm{~nm}) / \mathrm{Ni}(30 \mathrm{~nm}) / \mathrm{C}(3 \mathrm{~nm}) / \mathrm{SiC}$

(substrate) were prepared. The structures were annealed at $600^{\circ} \mathrm{C}\left(\mathrm{N}_{2}, 15 \mathrm{~min}\right.$. $)$ to form silicides. Annealing was followed by thermal treatment at different temperatures: $800^{\circ} \mathrm{C}, 950^{\circ} \mathrm{C}$, and $1000^{\circ} \mathrm{C}\left(\mathrm{N}_{2}, 3 \mathrm{~min}\right.$. $)$ to obtain ohmic contact $[15,16]$. Specific contact resistance and temperature used in second step of annealing are presented in Table 1

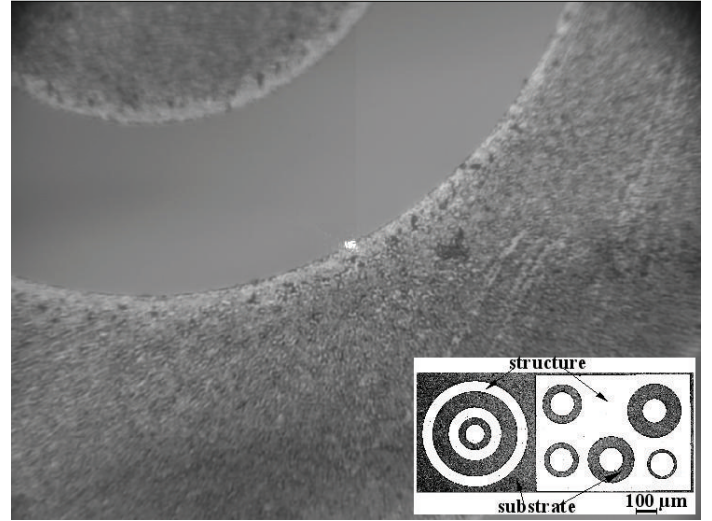

Figure 1: Example of microscopic image taken for nsc1_1. The glossy area corresponds to image of $4 \mathrm{H}-\mathrm{SiC}$ substrate, the rough one, to the structures. Small bright spot in the center shows the image of focused laser light. Inset: schematic picture of structures arrangement on samples from $n s c 1$ series.

for samples investigated with Raman spectroscopy hereafter signed by: $n s c 1 \_1, n s c 1 \_2$, and $n s c 1 \_3$.

The example of microscopic image and scheme of the sample as an inset is shown in Figure 1. The glossy area corresponds to image of $4 \mathrm{H}-\mathrm{SiC}$ substrate, the rough oneto the area covered with sequence of described above $\mathrm{Ni} / \mathrm{Si}$ layers. Hereafter this area will be called structure. Small bright spot in the center shows focused laser light.

The samples were characterized by means of transmission electron microscopy (TEM) and secondary ion mass spectrometry (SIMS). Both methods showed changes in the structure of $\mathrm{Ni} / \mathrm{Si} / \mathrm{Ni} / \mathrm{Si}$ layer sequence upon thermal treatment and presence of carbon layer between siliconcarbide substrate and silicide layer [17].

2.2. Apparatus. The Raman scattering was measured with MonoVista Raman microspectrometer (Spectroscopy and Imaging $\mathrm{GmbH}$, Germany). The micro-Raman spectrometer was based on Olympus BX51 microscope equipped with the following types of objectives:

(i) magnification: 20x, 50x and $100 \mathrm{x}$, for visible light (VIS);

(ii) magnification 40x, designed for ultraviolet (UVB).

Images from microscope were recorded with imaging camera TM 2040GE (JAI, Japan) with 16 bit AD image conversion. The spectral part of the micro-Raman spectrometer was based on SpectraPro 2750i spectrograph (Princeton Instruments, USA) with triple grating turret. The turret is equipped with three gratings:

(i) 1800 lines/mm and 2400 lines/mm blazed for visible spectral range;

(ii) 3600 lines/mm blazed for ultraviolet $(250 \mathrm{~nm})$.

The spectral detection was done with CCD camera Spec10 System (Princeton Instruments). Maximum efficiency of the camera was at $250 \mathrm{~nm}$. The $x, y, z$ motor driven (Ludl 
TABLE 1: Annealing temperature used in the second step of the fabrication process $\left({ }^{\circ} \mathrm{C}\right)$ and specific contact resistance $\left(\Omega \mathrm{cm}^{2}\right)$ of investigated samples_-nsc1_1, nsc1_3, and $n s c 1 \_2$.

\begin{tabular}{lcc}
\hline Sample & Annealing temperature $\left({ }^{\circ} \mathrm{C}\right)$ & Specific contact resistance $\left(\Omega \mathrm{cm}^{2}\right)$ \\
\hline$n s c 1 \_1$ & 1000 & $2.0 \pm 0.15 \times 10^{-4}$ \\
$n s c 1 \_3$ & 950 & $3.4 \pm 0.40 \times 10^{-4}$ \\
$n s c 1 \_2$ & 800 & $3.9 \pm 1.00 \times 10^{-4}$ \\
\hline
\end{tabular}

Electronics, USA) stage allowed positioning with $20 \mathrm{~nm}$ step in $x$ or $y$ direction and $50 \mathrm{~nm}$ in $z$ direction.

2.3. Experimental Conditions. As a fundamental wavelengths (excitation) the visible line of $\mathrm{Ar}^{+}$laser $\lambda=488 \mathrm{~nm}$ (INNOVA 90C FRED, Coherent Inc., USA) and its second harmonic $\lambda=244 \mathrm{~nm}$ were used. The power of the laser beam on the sample was below $1 \mathrm{~mW}$ for each fundamental wavelength. Visible Raman spectra were recorded with the grating with 1800 lines $/ \mathrm{mm}$ and the objective lens of magnification equal to $100 \mathrm{x}$ designed for visible spectral range. In the case of ultraviolet excitation the UV objective lens (magnification 40x) and blazed for $250 \mathrm{~nm}$ grating with 3600 lines $/ \mathrm{mm}$ were used. The exposition time used for measurement of single spectrum was equal to 1 hour. In the case of linear scan the exposition time for one spectrum was reduced to 15 minutes.

2.4. Spectra Analysis. Measured spectra were mathematically corrected prior to analysis. This mathematical treatment included offset removing, baseline correction, and normalization of intensities to value equal to 1 . The mathematical processing made possible the comparison of following features: the shapes of measured spectra and $D$-to- $G$ intensity ratio. Mathematical treatment of measured Raman spectra was done with Grams Suite v. 8 program (Thermo Scientific, USA). The analysis of normalized spectra was performed by fitting Lorentzian function with open source program Fityk 0.8.6 (Levenberg-Marquardt algorithm).

\section{Results}

In Figure 2 an example of scan performed in plane of $\mathrm{SiC} / \mathrm{C}$ interface is presented. The direction of the scan was perpendicular to the edge of the structure. The measurement was done for $n s c 1$ 1 1 along $y$ coordinate in this particular case. Position $y=0 \mu \mathrm{m}$ corresponds to the edge of the structure, $y<0 \mu \mathrm{m}$, to laser beam focused on the area covered with sequence of layers, $y>0 \mu \mathrm{m}$, to laser beam focused on $\mathrm{SiC}$ substrate outside of the covered area. Panel (a) presents measured spectra as 3D surface, panel (b) is corresponding map. Panel (c) presents an example of measured spectrum with color scale used in panels (a) and (b). It is clearly visible that spectra change in the vicinity of $y=0 \mu \mathrm{m}$. Vicinity means here about $\pm 1 \mu \mathrm{m}$. Starting from negative values of $y$-coordinate: main Raman bands observed for carbon structures, $D$ and $G$, are changing to standard twophonon Raman scattering of $4 \mathrm{H}-\mathrm{SiC}$ [18] for positive values of $y$. The data obtained from spatial scans performed for other samples, $n s c 1 \_2$ and $n s c 1 \_3$, are very similar.

Normalized Raman spectra of carbon structures measured for different samples are presented in Figure 3. $D$ band has the maximum placed at about $1350 \mathrm{~cm}^{-1}$ in the case of each sample. The shape of this band is symmetrical. $D$ bands recorded for different samples have different values of FWHM. Differences between $G$ band recorded for different samples concern the position of the maximum of the band and its halfwidth. Samples $n s c l_{-} 1_{\text {and }} n s c 1_{-} 3$ have asymmetric $G$ band with maximum placed at about $1580 \mathrm{~cm}^{-1}$. $G$ band observed for $n s c 1 \_$has symmetric shape but its maximum is shifted to about $1600 \mathrm{~cm}^{-1}$. The signalto-noise ratio in the case of $n s c 12$ is unfavorable. Such effect in the case of nanocrystalline graphite in ohmic contacts was already reported [14]. Based on mathematical treatment detailed analysis of the spectra is presented in part Section 4 .

Additional information about carbon structure can be derived from $2 D$ band placed around $2700 \mathrm{~cm}^{-1}$ [19]. This band was observed for $n s c 1 \_1$ and $n s c 1 \_3$, whereas for $n s c 12$ weak increase of the background was detected in the corresponding range of Raman shift. In Figure 4 are presented normalized Raman spectra recorded for all samples. Due to low intensity of the band around Raman shift $2700 \mathrm{~cm}^{-1}$ and unfavorable signal-to-noise ratio $2 D$ band in the case of $n s c 122$ must be treated as negligible. The maxima of $2 D$ band observed for $n s c 1_{-} 1$ and $n s c 1 \_3$ had the maxima almost at the same value of Raman shift (see Figure 4). Spectra show small difference in FWHM, namely the band observed for $n s c 1 \_3$ is broader in comparison with the band recorded for $n s c 1 \_1$. The difference between spectra was observed on the left slope of $2 D$ band. The "hole" observed for all samples had the maximum at the same value of Raman shift (about $2715 \mathrm{~cm}^{-1}$ ). This kind of hole was not observed in spectra measured from these parts of the sample that were not covered with carbon and silicide layers. Because of this the origin of the hole should be treated as real and related to the presence carbon or/and silicide layers. The detailed origin of the effect is for authors not unequivocal and it will be discussed in subsequent paper.

In Figure 5 are presented normalized Raman spectra measured with application of UV excitation $(\lambda=244 \mathrm{~nm})$. In panel (a) are presented spectra measured for $n s c 1 \_1$, in panel (b) for $n s c 1 \_3$ and in panel (c) for $n s c 1$ 2. The arrows in panels (a) and (b) are placed in the position corresponding to maxima of carbon bands. The arrow in panel (c) is placed at about $1605 \mathrm{~cm}^{-1}$. For this value of Raman shift the maximum of $G$ band is expected for nanocrystalline graphite. In the case of each sample spectra were measured at different position with respect to the edge of the structure: 


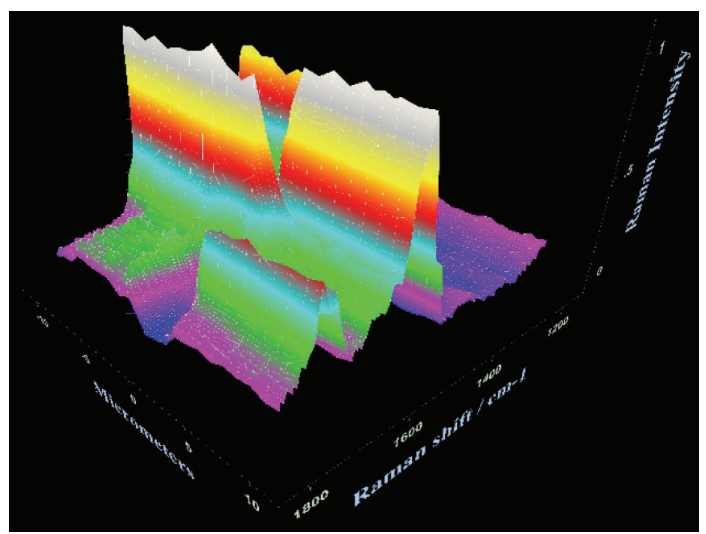

(a)

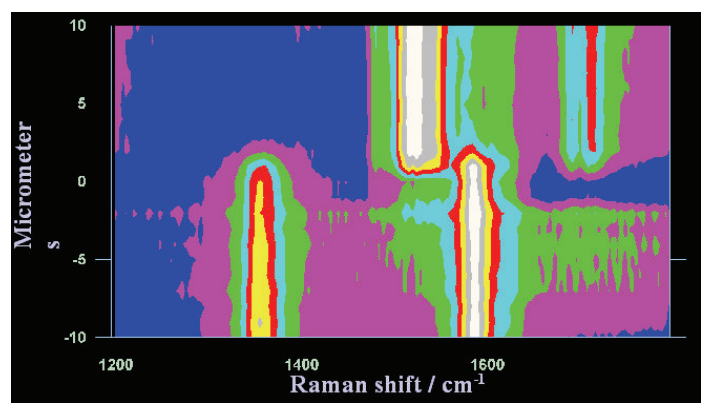

(b)

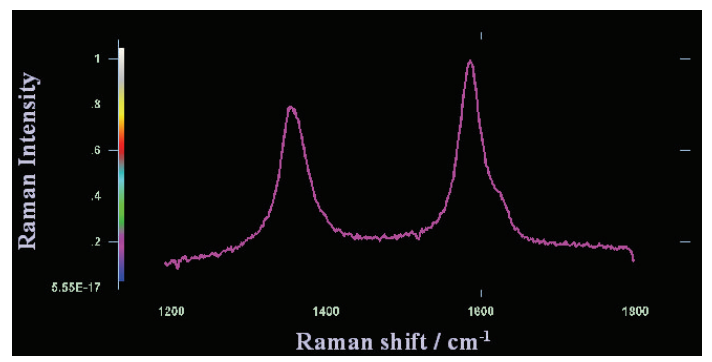

(c)

Figure 2: Example of $y$-scan (parallel to SiC/C interface and perpendicular to structure edge) measured for $n s c 1 \_1$. Position $y=0 \mu \mathrm{m}$ corresponds to the edge of the structure, $y<0 \mu \mathrm{m}-$ to laser beam focused on the area covered with sequence of layers, $y>0 \mu \mathrm{m}$ - to laser beam focused outside of the structure. Panel (a) presents measured spectra as 3D-surface, panel (b) — corresponding map, and panel (c) —example of Raman spectrum and color scale.

outside of the structure (blue line), on the edge (green line), on the structure near the edge (red line) and on the structure far from the edge (black line). In the cases of $n s c 1 \_1$ and $n s c 1$ 3 samples the carbon band appears around $1590 \mathrm{~cm}^{-1}$. The intensity of the band increases with the increase of the distance from the edge of the structure. In the case of $n s c 12$ very weak signal with maximum slightly above $1600 \mathrm{~cm}^{-1}$ appears for the measurement "on the structure far from the edge." Spectra registered in the vicinity of the edge are mainly composed of two-phonon scattering generated by $4 \mathrm{H}-\mathrm{SiC}$. Numerous narrow lines in UV Raman spectra were already observed by investigation of carbon inclusions in

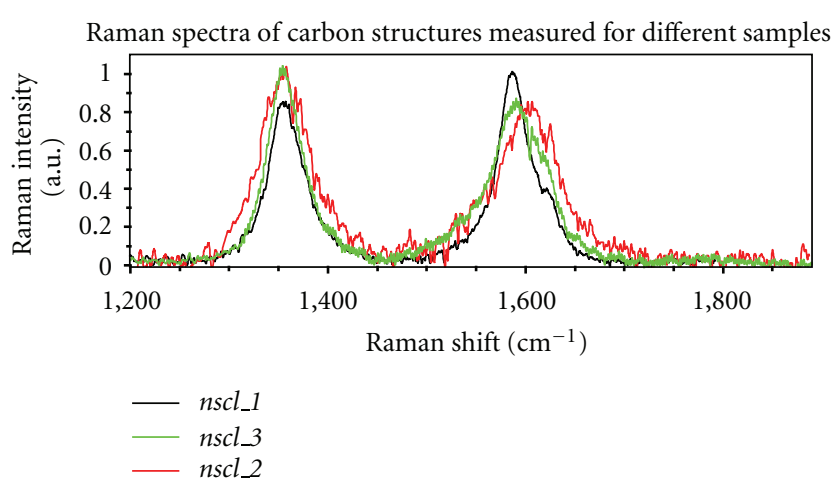

FIgURE 3: Comparison of normalized Raman spectra of carbon structures measured for different samples. nsc1_1-black line, $n s c 1 \_3$ - green line, and $n s c 1 \_2$-red line. The excitation wavelength was equal to $488 \mathrm{~nm}$.

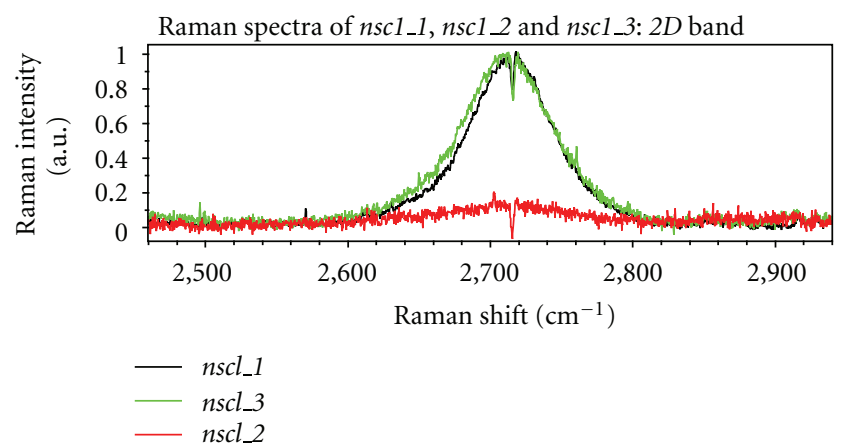

FIGURE 4: Comparison of normalized Raman spectra observed for $n s c 1_{1} 1, n s c 1 \_3$, and $n s c 1 \_2$ in the range around $\sim 2700 \mathrm{~cm}^{-1}(2 D$ band). In the case of $n s c 12$ the intensity of the signal observed in this range of Raman shift was so weak that the intensity of $2 D$ band was negligible. Excitation wavelength $488 \mathrm{~nm}$.

$\mathrm{SiC} / \mathrm{SiO}_{2}$ interface [20]. Since the origin of these lines is not related to the carbon layer, the discussion concerning these lines is omitted. Also the signal from interface is taken into account. Raman signal from thin interface layer is usually very weak. Since the investigation of the interface structure do not belong to the main aim of this work it will be not discussed here.

\section{Discussion}

Figure 6 presents results of analysis of Raman spectra measured for all samples with visible excitation. Panel (a) shows results obtained for $n s c 1 \_1$, panel (b) for $n s c 13$, and panel (c) for $n s c 12$. The main plot in each panel presents experimental points (red) and fitted profiles (black line). The positions of profiles maxima are given in the panels. The upper inset compares experimental data with whole fitted function. Lower inset presents autocorrelation function. The number of Lorentzian fitting components necessary for proper spectra reproduction varies. In the case of $n s c 1 \_1$ three profiles are necessary, for $n s c 1$ _ 3 -four, and for nsc1 2-two. Generally, the shapes of fitted functions 


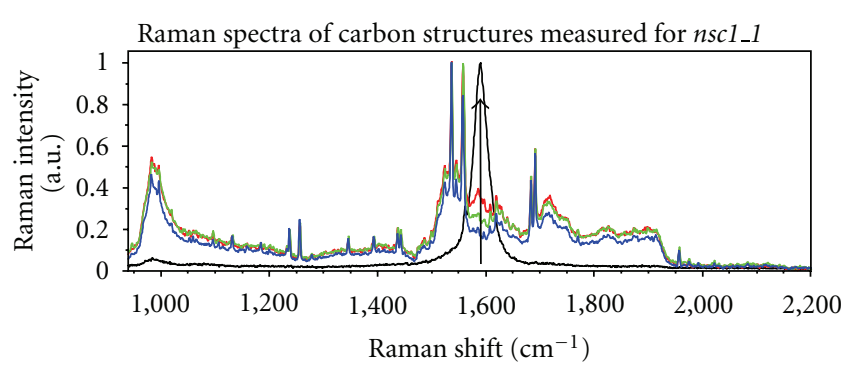

(a)

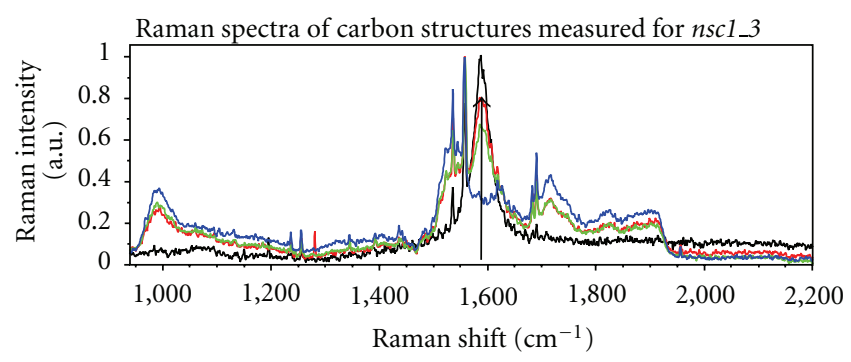

(b)

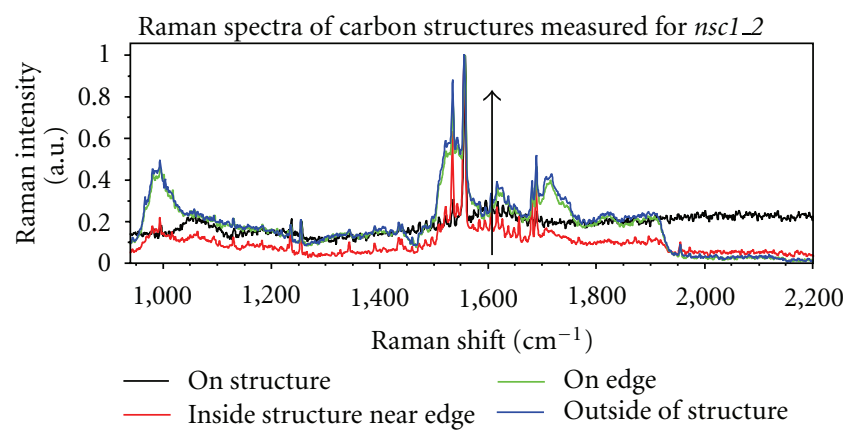

(c)

Figure 5: Comparison of normalized Raman spectra measured for different samples_-(a) $n s c 1 \_1$, (b) $n s c 1 \_3$, and (c) $n s c 1 \_2$ with UV excitation $(\lambda=244 \mathrm{~nm})$. In the case of each sample spectra were measured at different position with respect to the edge of the structure: outside of the structure (blue line), on the edge (green line), on the structure near the edge (red line), and on the structure far from the edge (black line). Arrows in panels (a) and (b) mark the maximum of observed carbon band. In the case of panel (c) arrow marks the position of $G$ band expected for nanocrystalline graphite.

follow the experimental data. Small differences between the experimental data and the fitted functions are visible in autocorrelation functions. The values presented in these insets were calculated by subtracting the fitted function from experimental data. Increase of the number of Lorentzian fitting components does not improve the quality of the fit in the case of any sample. The profile reproducing the "hole" in $G$ band of $n s c 1 \_3$ is shifted in the top of panel (b).

Generally, recorded for nsc1_1 Raman spectra are very similar to the spectra found in literature and observed for samples after similar temperature treatment [14]. Position of $G$ band observed for $n s c 12$ is shifted towards larger values of Raman shift and equals to about $1603 \mathrm{~cm}^{-1}$. This value corresponds to the maximum observed for

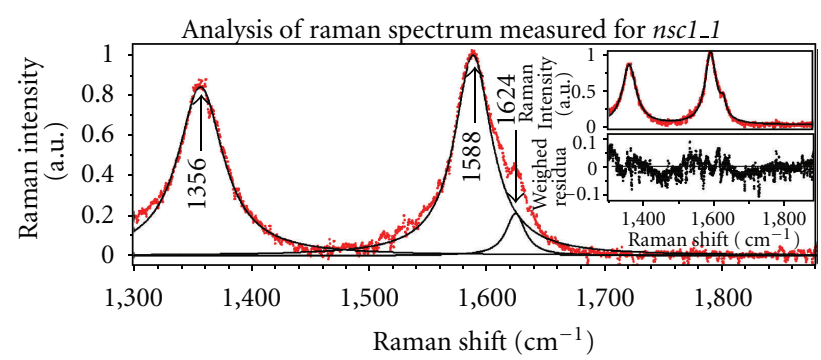

(a)

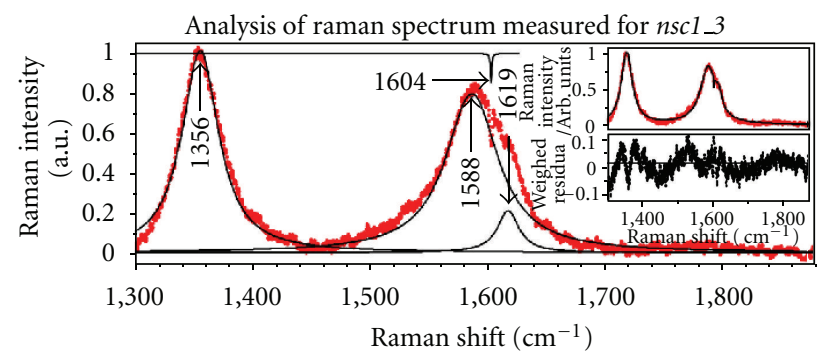

(b)

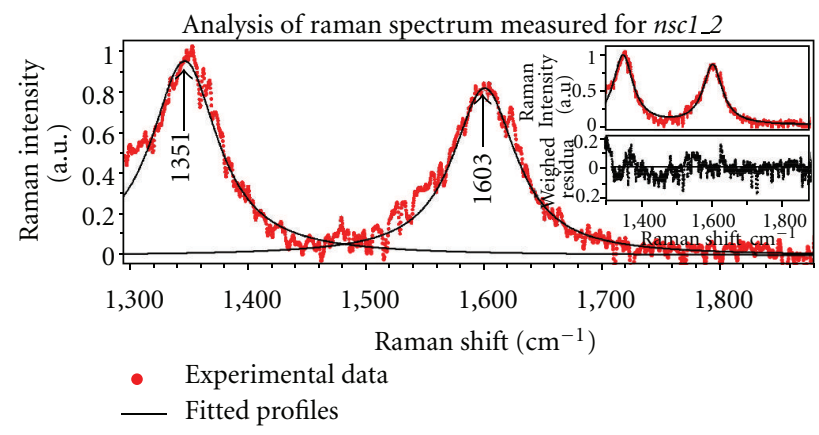

(c)

FIGURE 6: Analysis of Raman spectra in the range of Raman shift corresponding to $D$ and $G$ bands $\left(1300 \mathrm{~cm}^{-1} \div 1880 \mathrm{~cm}^{-1}\right)$ measured with visible excitation $(488 \mathrm{~nm})$-panel (a) nsc1_1, panel (b) $n s c 1 \_3$, and panel (c) $n s c 1 \_$. The main plot in each panel presents measured data (red points) and fitted Lorentzian components (black line). The maxima of profiles are given in the plot. Upper inset compares measured data (red points) with fitted function (black line). Lower inset presents autocorrelation function as a certificate of quality of fitting procedure.

nanocrystalline graphite $[21,22]$. Shift of the maximum position of $G$ observed for nanocrystalline graphite results from convolution of $G$ and $D^{\prime}$ bands so it is impossible to split observed band into unequivocal components [21]. In the case of $n s c 1 \_$it is possible that observed $G$ band consists of even three components: "pure $G$, , $D^{\prime}$ and probably small addition of Ni-GIC.

In Table 3 there is presented intensity ratio of bands $D$ and $G\left(I\left(L_{1}\right) / I\left(L_{2}\right)\right)$ and $D^{\prime}$ to $G\left(I\left(L_{3}\right) / I\left(L_{2}\right)\right)$. Since FWHM of carbon bands contains the information about different structures (like 5-member rings) and the height of the band contains the information about the concentration of the main structure [21] it is more reliable to compare heights of fitted profiles instead of profiles area. The values 
TABLe 2: Positions of maxima and FWHM's (in $\mathrm{cm}^{-1}$ ) of profiles obtained from fitted Lorentzian components. In brackets there are historical signs of carbon bands. In the case of $n s c 12$ it was impossible to split $G$ band into components, so the maximum and FWHM are given for $L_{2}+L_{3}$. The data of the profile used to model the hole in $n s c 1 \_3$ were omitted because this profile is not discussed in the paper.

\begin{tabular}{|c|c|c|c|c|c|c|}
\hline \multirow{2}{*}{ Profile number } & \multicolumn{2}{|c|}{$n s c 1 \_1$} & \multicolumn{2}{|c|}{$n s c 1 \_3$} & \multicolumn{2}{|c|}{$n s c 1 \_2$} \\
\hline & $\operatorname{Max} .\left(\mathrm{cm}^{-1}\right)$ & FWHM $\left(\mathrm{cm}^{-1}\right)$ & $\operatorname{Max} .\left(\mathrm{cm}^{-1}\right)$ & FWHM $\left(\mathrm{cm}^{-1}\right)$ & $\operatorname{Max} .\left(\mathrm{cm}^{-1}\right)$ & FWHM $\left(\mathrm{cm}^{-1}\right)$ \\
\hline$L_{1}(D)$ & 1356,1 & 46.8 & 1356,0 & 38.3 & 1351,3 & 68.4 \\
\hline$L_{2}(G)$ & 1587,9 & 38.4 & 1587.7 & 54.2 & 16030 & 650 \\
\hline$L_{3}\left(D^{\prime}\right)$ & 1623,9 & 19.6 & 1619.6 & 22.0 & & \\
\hline
\end{tabular}

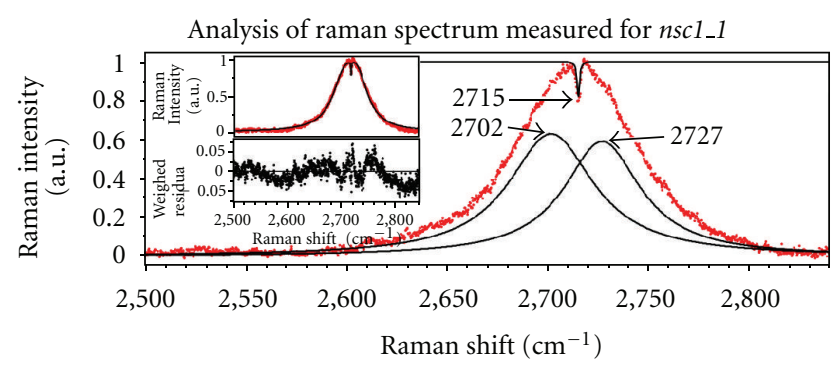

(a)

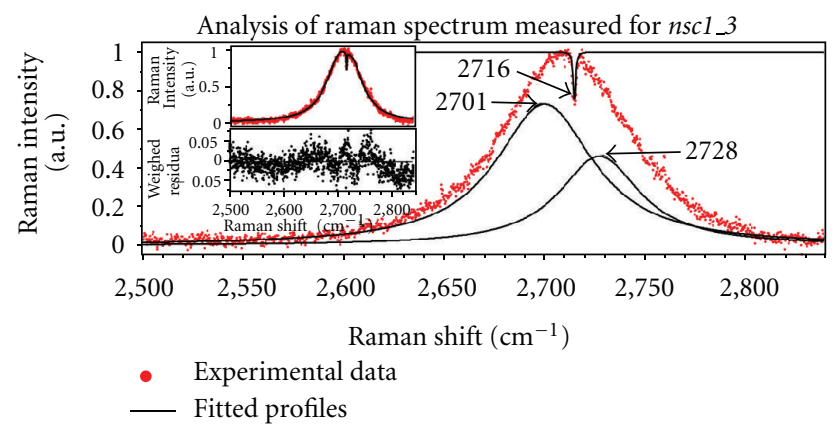

(b)

FIgURe 7: Analysis of Raman spectra in the range corresponding to $2 D$ band $\left(2500 \mathrm{~cm}^{-1} \div 2880 \mathrm{~cm}^{-1}\right)$ measured with visible excitation (488 nm) - panel (a) nsc1_1, panel (b) $n s c 1 \_3$. The main plot in each panel presents measured data (red points) and fitted Lorentzian component (black line). The maxima of Lorentzian components are given in the plot. The component reproducing the "hole" in the band is shifted up to the level equal to 1. Upper inset compares measured data (red points) with fitted function (black line). Lower inset presents autocorrelation function as a certificate of quality of fitting procedure. In the case of $n s c 12$ the signal corresponding to $2 \mathrm{D}$ band was negligible and due to unfavorable signal-to-noise ratio was not analyzed.

TABLe 3: Intensity ratio of bands: $D$ to $G\left(I\left(L_{1}\right) / I\left(L_{2}\right)\right)$ and $D^{\prime}$ to $G$ $\left(I\left(L_{3}\right) / I\left(L_{2}\right)\right)$. Since heights in maxima of bands offer more reliable information, due to smaller impact from different structures, the ratio of maxima of profiles is presented.

\begin{tabular}{lccc}
\hline Intensity ratio & $n s c 1 \_1$ & $n s c 1 \_3$ & $n s c 1 \_2$ \\
\hline$I\left(L_{1}\right) / I\left(L_{2}\right)$ & 0,84 & 1,27 & 1,16 \\
$I\left(L_{3}\right) / I\left(L_{2}\right)$ & 0,21 & 0,28 & - \\
\hline
\end{tabular}

presented in Table 3 refer to the ratio of fitted Lorentzian heights. The ratio $I\left(L_{1}\right) / I\left(L_{2}\right)$ is smaller for $n s c 1_{-} 1$ than for

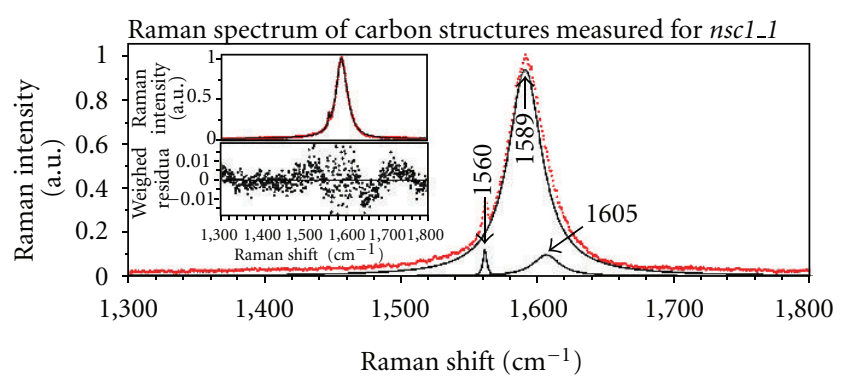

(a)

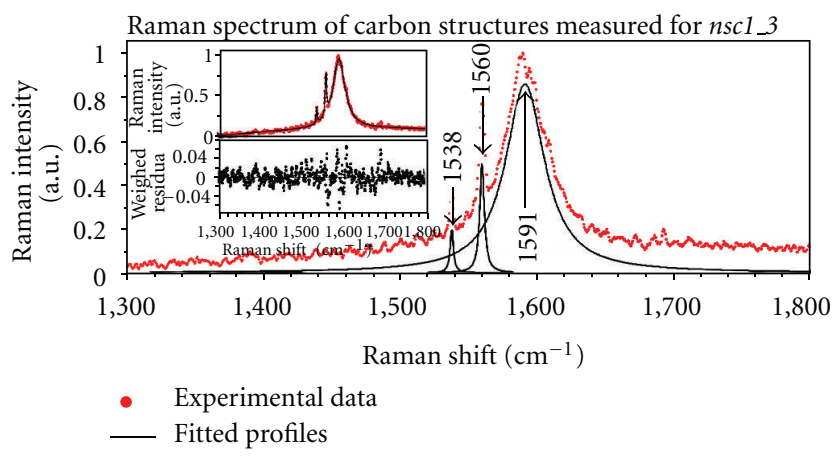

(b)

Figure 8: Analysis of Raman spectra in the range of Raman shift $1300 \mathrm{~cm}^{-1} \div 1800 \mathrm{~cm}^{-1}$ measured with ultraviolet excitation $\left(244 \mathrm{~nm}\right.$ )_panel (a) $n s c 1 \_1$, panel (b) $n s c 1$ _3. The main plot in each panel presents measured data (red points) and fitted Lorentzian components (black line). The maxima of Lorentzian fitting components are given in the plot. Upper inset compares measured data (red points) with fitted function (black line). Lower inset presents autocorrelation function as a certificate of quality of fitting procedure. The signal recorded for $n s c 1 \_2$ sample has to small intensity to be analyzed.

nsc1_3. This difference shows larger graphitization degree in the case of $n s c 1_{-} 1$. In the case of $n s c 12$ the value given in Table 2 can be affected by impossibility of splitting observed " $G$ " band into components. However, presented in Table 2 descending FWHM's values $\left(n s c 1 \_2 \rightarrow n s c 1 \_3 \rightarrow\right.$ $\left.n s c 1 \_1\right)$ of $G$ band suggest increase of the graphitization degree in the row: $n s c 1 \_2 \rightarrow n s c 1 \_3 \rightarrow n s c 1 \_1$. The difference in maximum intensity ratio of $I\left(L_{3}\right) / I\left(L_{2}\right)$ obtained for $n s c 1_{-} 1$ and $n s c 1 \_3$ reflects smaller concentration of carbon structures responsible for $D^{\prime}$ band in $n s c 1 \_1$. This decrease of concentration of carbon structures responsible for $D^{\prime}$ band is not fully compensated by increase of concentration of $\mathrm{Ni}$ GIC species. 
TABLE 4: Summary of analysis of $2 D$ band. First column—-the name of the sample, second and third columns-position of the maximum of first Lorentzian fitting component $\left(L_{1}\right)$ and its FWHM, respectively, fourth and fifth columns-position of the maximum and FWHM of second Lorentzian fitting component $\left(L_{2}\right)$, respectively, and sixth column—ratio of intensities: $I\left(L_{1}\right) / I\left(L_{2}\right)$. Values of maxima positions and FWHM's in $\mathrm{cm}^{-1}$. The intensities used to calculate values presented in sixth column-heights of profiles. Data of profiles used to model the hole are omitted because this feature is not discussed in the paper.

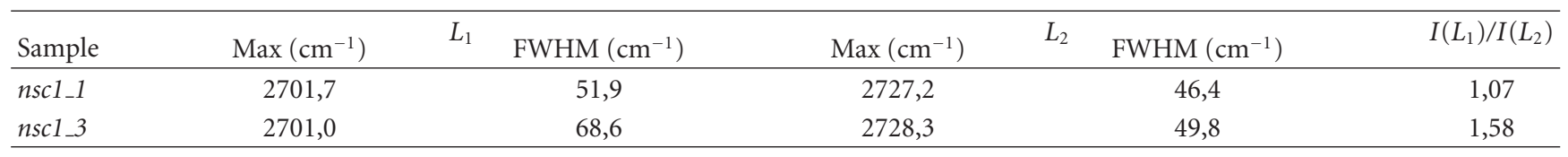

In Figure 7 there are presented results of the analysis of $2 D$ band measured for $n s c l_{-} 1$ and $n s c 1 \_3$. Panel (a) presents the data obtained for $n s c 1_{-} 1$, (b)—nsc1_3. Due to negligible intensity of UV Raman spectra obtained for sample nscl 2 (see Figure 5(c)) the spectra measured for this sample were not analyzed. The convention used in Figure 7 is the same as in Figure 6. Main plots show experimental points and fitted Lorentzian components with given maxima positions. Upper insets compare the experimental data with whole fitted function. Lower insets show the autocorrelation functions. Three Lorentzian fitting components are necessary for reasonable reproduction of $2 D$ band in the case of each sample. One of these profiles is used to model the "hole" placed near maximum of the band. The profiles reproducing the "hole" are shifted up to the normalization limit. The shape of the fitted function corresponds to distribution of experimental points. Small differences between fitted function and experimental data are visible in autocorrelation functions. The increase of the number of Lorentzian components does not reduce small discrepancies between fitted function and experimental data.

In Table 4 results of analysis of $2 D$ band are presented. The function used to reproduce the hole is omitted because the origin of the hole is not discussed. Position of the maximum of $L_{1}$ Lorentzian component is similar for both samples: the difference between maxima position is equal to $0.7 \mathrm{~cm}^{-1}$. In the case of $L_{2}$ maximum position obtained for $n s c 1 \_1$ is shifted towards smaller values in comparison with $n s c 1$ 3. The difference between maxima positions of $L_{2}$ component is equal to $1.1 \mathrm{~cm}^{-1}$. Intensity ratio $I\left(L_{1}\right) / I\left(L_{2}\right)$ was calculated as the ratio of the heights of Lorentzian fitting components. The contribution of $L_{1}$ component in the case of $n s c 1 \_3$ is significantly larger in comparison with $n s c 1$ 1. Generally the reproduction of $2 D$ band generated by graphitic structures requires four Lorentzian components $[19,23]$. This rule can be modified by interaction with substrate or structure [24]. For example: $2 D$ band of "few layers graphene" looks very similar to $2 D$ bands observed for $n s c 1 \_1$ and $n s c 1 \_3$ [24]. Small differences between maxima positions reported in literature and observed here may result from dispersive behavior of $D$ and, of course, $2 D$ bands. The typical wavelength of fundamental line reported in literature equals $514.5 \mathrm{~nm}$ whereas here authors used $488 \mathrm{~nm}$. The components of $D$ band: $D_{1}$ and $D_{2}$ are related to mutual orientation of $A$ and $B$ layers [25]. The profiles fitted to $2 D$ band correspond to $2 D_{1}$ and $2 D_{2}$ overtones. The shape of $2 D$ band depends on excitation wavelength and number of "graphene layers" in the sample $[19,26]$.
$2 D$ band generated by "single graphene layer" fits single Lorentzian function $[19,25,27]$. However, it was recently shown that even "graphene flakes" can generate $2 D$ bands composed of more than one Lorentzian fitting component [28]. The interlayer distance in graphite equals to about $0.335 \mathrm{~nm}$ [29] and slightly varies with stacking order [30]. Since the processes of migration of carbon atoms from $\mathrm{SiC}$ interface and decomposition of silicon-carbide substrate are going simultaneously one should not expect drastic change of the thickness of deposited carbon layer. Also the rate of these processes is so small that cannot significantly affect the thickness of carbon layer. For example formation of "graphene layer" at $1450^{\circ} \mathrm{C}$ requires 1 hour [31]. This is in agreement with data obtained TEM that showed the carbon layer between $4 \mathrm{H}-\mathrm{SiC}$ substrate and silicide layer [17]. Taking into account thickness of deposited C-layer equal to about $3 \mathrm{~nm}$ one can expect carbon film placed on $\mathrm{SiC}$ substrate has thickness corresponding to $8-10$ carbon layers. The shape of $2 D$ band is also a function of staking order [32]. Although the shape of $2 D$ band depends on excitation wavelengths there is one common feature observed for the band in the cases of all reported excitations [32]. The maximum of $2 D$ band is shifted towards smaller values of Raman shift in the case of $A B C$ stacking order whereas the maximum of $2 \mathrm{D}$ band observed for $\mathrm{ABA}$ stacking order is placed at larger values of Raman shift [32]. This difference increases with excitation energy [32]. Natural graphite is a mixture of different species. The most important are hexagonal ( $\alpha$ or Bernal) structure and rhombohedral $(\beta)$ structure. The content of $\beta$-form varies typically from 5 to $15 \%[33,34]$. The domains having $\mathrm{ABC}$ stacking order are stable up to temperatures above $800^{\circ} \mathrm{C}$ [32]. The conversion of rhombohedral graphite to the hexagonal form occurs effectively at temperature higher than $1025^{\circ} \mathrm{C}$ [35]. The rhombohedral phase may be completely converted to the hexagonal one in the case of heating above $3000^{\circ} \mathrm{C}$ [36]. The preferential formation of rhombohedral graphite on $\mathrm{SiC}$ interface was observed during the process of thermal decomposition of silicon-carbide substrate [37]. The most probable explanation of spectral differences between the samples $n s c 1 \_1$ and $n s c 1 \_3$ in the range corresponding to $2 D$ band is following: the different content of rhombohedral and hexagonal phases in $n s c 1 \_1$ and $n s c 1 \_3$ should be the reason of the differences observed for $2 D$ band.

The last problem to be discussed for measurements carried out for visible fundamental wavelength is the negligible 
TABLE 5: Analysis of carbon band observed with irradiation by UV laser. $L_{1}$ and $L_{2}$ Lorentzian fitting components used to reproduce shape of main carbon bands, $I\left(L_{2}\right) / I\left(L_{1}\right)-L_{2}$ to $L_{1}$ intensity ratio. $L_{3}$ and $L_{4}$ Lorentzian fitting components used to reproduce narrow lines, $I\left(L_{3}\right) / I\left(L_{1}\right)-L_{3}$ to $L_{1}$ intensity ratio, $I\left(L_{4}\right) / I\left(L_{1}\right)-L_{4}$ to $L_{1}$ intensity ratio. Maxima positions and FWHMS-in $\mathrm{cm}^{-1}$. Analyzed spectra were mathematically corrected for offset and normalized to 1 prior to analysis.

\begin{tabular}{|c|c|c|c|c|c|c|c|c|c|c|c|}
\hline \multirow[b]{2}{*}{ Sample } & \multicolumn{2}{|c|}{$L_{1}$} & \multicolumn{2}{|c|}{$L_{2}$} & \multirow[b]{2}{*}{$I\left(L_{2}\right) / I\left(L_{1}\right)$} & \multicolumn{2}{|c|}{$L_{3}$} & \multicolumn{4}{|c|}{$L_{4}$} \\
\hline & $\begin{array}{l}\text { Max. } \\
\left(\mathrm{cm}^{-1}\right)\end{array}$ & $\begin{array}{c}\text { FWHM } \\
\left(\mathrm{cm}^{-1}\right)\end{array}$ & $\begin{array}{c}\text { Max. } \\
\left(\mathrm{cm}^{-1}\right)\end{array}$ & $\begin{array}{l}\text { FWHM } \\
\left(\mathrm{cm}^{-1}\right)\end{array}$ & & $\begin{array}{l}\text { Max. } \\
\left(\mathrm{cm}^{-1}\right)\end{array}$ & $\begin{array}{l}\text { FWHM } \\
\left(\mathrm{cm}^{-1}\right)\end{array}$ & $I\left(L_{3}\right) / I\left(L_{1}\right)$ & $\begin{array}{l}\text { Max. } \\
\left(\mathrm{cm}^{-1}\right)\end{array}$ & $\begin{array}{l}\text { FWHM } \\
\left(\mathrm{cm}^{-1}\right)\end{array}$ & $I\left(L_{4}\right) / I\left(L_{1}\right)$ \\
\hline$n s c 1 \_1$ & 1589 & 30 & 1605 & 21 & 0,09 & - & - & - & 1560 & 3 & 0,12 \\
\hline$n s c 1 \_3$ & 1591 & 35 & - & - & - & 1538 & 3 & 0,24 & 1560 & 4 & 0,58 \\
\hline
\end{tabular}

intensity of $2 D$ band in the case of $n s c 1$ 2. In following cases $2 D$ band is not observed:

(i) for amorphous carbon $(a-\mathrm{C})$;

(ii) for tetrahedral amorphous carbon $(t a-C)$ [19].

However, for $a-C$ and $t a-C$ the intensity of $D$ band should be negligible or at least much smaller than the intensity of $G$ band [21] which is not valid for $n s c 12$. The other possible explanation of negligible intensity observed for $2 D$ band in the spectrum of $n s c 12$ is the dependence between intensity of $2 D$ band and the type of metallic layer placed on carbon structure [38]. Such metallic layer may reduce the intensity of $2 D$ band [38]. The intensity of $2 D$ band in some cases is much smaller than the intensity of $G$ band $[14,38]$, or even has the tendency to disappear like for nanocrystalline graphite [7]. Since the intensities of main carbon bands $(D$ and $G$ ) were small in the case of $n s c 1.2$ the intensity of $2 D$ band was too weak to obtain good signalto-noise ratio, although the band seems to be present. The annealing temperature used in the second step of $n s c 12$ thermal treatment $\left(800^{\circ} \mathrm{C}\right)$ is the lower limit when $2 \mathrm{D}$ band can appear in ohmic contacts $[14,38]$. One more factor which can influence the intensity of observed Raman spectra is heating time used in ohmic contact formation. According to literature concerning Raman study it usually takes 2 hours $[14,38]$, whereas in the case of $n s c 1$ series of samples it was 15 minutes at $600^{\circ} \mathrm{C}$ and additional 3 minutes for the second step $\left(800^{\circ} \mathrm{C}\right.$ and above). The first step of thermal treatment is below the reported temperature limit necessary for $2 D$ band appearance.

In Figure 8, the results of analysis of Raman spectra measured with UV irradiation are presented. Panel (a) shows the data obtained for $n s c 1 \_1$, (b) - nscl_3. The main plot in each panel shows experimental data (red points) together with fitted profiles (black line). The maxima positions are listened in the plot. The upper inset in each panel compares the experimental points with fitted function. The lower inset presents the autocorrelation function. In the case of each sample fitted function reproduces quite well the shape of measured spectrum. Small differences between experimental data and fitted function are visible in autocorrelation function.

In Table 5 results of analysis of Raman bands observed with irradiation by UV laser light "on the structures far from the edge" are presented. The main band observed for irradiation "on the structure far from the edge" is well reconstructed by two Lorentzian fitting components in the case of $n s c 1_{-} 1$ and one Lorentzian fitting component in the case of $n s c 1$ 3. $L_{1}$ profile has the maximum at Raman shift equal to $\sim 1589 \mathrm{~cm}^{-1}$ in the case of $n s c 1 \_1$ and $\sim 1591$ $\mathrm{cm}^{-1}$ in the case of $n s c 13$. The maximum position of the band corresponds to the maxima observed for $G$ band of graphite layers $[19,23]$. The difference in the position of maximum of the band reflects small structural changes between the layers appearing on the surface of $n s c 1$ and $n s c 1$-3 samples. This kind of dependence was already observed [23]. The decrease of FWHM from $35 \mathrm{~cm}^{-1}$ for $n s c 1 \_3$ to $30 \mathrm{~cm}^{-1}$ for $n s c 1 \_1$ suggests larger homogeneity for $n s c 1_{-} 1$. The second Lorentzian fitting component $\left(L_{2}\right)$ used in reproduction of spectrum measured for $n s c l_{\_} 1$ has the maximum at $1605 \mathrm{~cm}^{-1}$ and corresponds to the band reported for nanocrystalline graphite [21]. The FWHM obtained $\left(21 \mathrm{~cm}^{-1}\right)$ for $L_{2}$ component is similar to the values obtained for $L_{3}$ profile from Table 2 and about three times smaller than FWHM obtained for nsc1_2 from VIS irradiation.

The main problem to be discussed is the type of structure which generates Raman scattering observed in the case of irradiation with ultraviolet laser line. Annealing at temperature higher than $600^{\circ} \mathrm{C}$ leads not only to the formation of silicides but also to redistribution of carbon atoms $[6,11,13]$. The layer of nickel-silicides is the mixture of silicides and carbon structures. The other important feature is graphite thin layer placed on the free surface of silicide layer. Annealing at the temperature higher than $950^{\circ} \mathrm{C}$ leads to changes in the structure of graphite species placed in Ni-silicide layer [13]. The dimensions of clusters are larger. Large clusters are concentrated inside the silicide layer near $\mathrm{SiC} / \mathrm{Ni}$-silicide interface. Optical properties of both Nisilicide layer mixed with carbon and graphite thin layer placed on free surface of Ni-silicide film are important in the interpretation of ultraviolet Raman spectra.

Thin graphite film does not decrease significantly the intensity of the light in ultraviolet and visible spectral range [39-41]. The silicide film with thickness of about $100 \mathrm{~nm}$ is transparent in the visible and ultraviolet spectral ranges $[8,42-44]$. Silicides mixed with carbon species show absorption which increases significantly if spectral range is changed from visible to ultraviolet [45]. Also the mixture of nanocrystalline graphite and diamond-like structures has significantly larger absorption in UV than in visible spectral range [46]. Coming back to Raman spectra: the main Lorentzian fitting component $\left(L_{1}\right)$ reproduces the spectra of 
$n s c 1 \_1$ and $n s c 1 \_3$ coming from thin graphite layer placed on the free surface of silicide because $\mathrm{Ni}$-silicide film mixed with carbon strongly absorbs UV light hindering effective scattering from the carbon layer placed at the $4 \mathrm{H}-\mathrm{SiC} / \mathrm{Ni}-$ silicide interface. The other Lorentzian fitting component $\left(L_{2}\right)$ observed for $n s c 1 \_1$ corresponds to $G$ band coming from nanocrystalline graphite located inside the Ni-silicide film. The absence of $D$ or $T$ band in measured UV Raman spectra can be explained by the quality of graphite layer, which means by negligible concentration of defects. In the case of nanocrystalline species placed inside the silicide layer the vibrations of carbon atoms placed at the border of nanocrystals can be modified by interaction with silicides. This kind of modification results in change of Raman spectrum.

Profiles $L_{3}$ and $L_{4}$ describe narrow lines with maxima at about $1538 \mathrm{~cm}^{-1}$ and $1560 \mathrm{~cm}^{-1}$, respectively. The halfwidth of these profiles, $3 \mathrm{~cm}^{-1}$ and $4 \mathrm{~cm}^{-1}$, can be treated as equal within accuracy of measurements with UV excitation. The line with maximum at about $1530 \mathrm{~cm}^{-1}$ was reported for nanographite species [47, 48]. The broad band from [47] can be associated with amorphous carbon [21]. The narrow line reported in [47] was assigned to armchair-shaped edge of graphite nanoribbon. Generally the lines with FWHM equal to a few $\mathrm{cm}^{-1}$ are typical traces of localized vibrational modes (LVM's) associated with defects of crystal structure [49]. Typical edges of graphite nanoparticles or nanoribbons are classified as arm-chair-shaped (A-shaped), zigzag-shaped (Zshaped), or mixed-shaped (M-shaped): a combination of Aand Z-shaped [49]. The line associated with Z-shaped edge expected at about $1450 \mathrm{~cm}^{-1}$ [48] was not observed here. Lines having maxima at $1530 \mathrm{~cm}^{-1}, 1531 \mathrm{~cm}^{-1}$ as well as around $1560 \mathrm{~cm}^{-1}\left(1556 \mathrm{~cm}^{-1}, 1558 \mathrm{~cm}^{-1}\right.$, and $\left.1567 \mathrm{~cm}^{-1}\right)$ were observed for polyenic backbone molecules [50]. The vibration around $1560 \mathrm{~cm}^{-1}$ was reported in UV-Raman spectra of polycyclic aromatic hydrocarbons (PAHs) are anthracene $\left(1567 \mathrm{~cm}^{-1}, 1562 \mathrm{~cm}^{-1}\right)[51,52]$, phenanthrene $\left(1563 \mathrm{~cm}^{-1}\right)$ [52], and pyrene $\left(1560 \mathrm{~cm}^{-1}, 1563 \mathrm{~cm}^{-1}\right)$ [51, 52]. Vibrations $1533 \mathrm{~cm}^{-1}$ in pentacene and $1570 \mathrm{~cm}^{-1}$ in perylene were classified as "aromatic C-C stretching" [53]. Taking into account summed-up above information we divide the carbon structures associated with lines: $1538 \mathrm{~cm}^{-1}$ and $1560 \mathrm{~cm}^{-1}$ into two types:

(i) ribbon- or chain-like;

(ii) PAH-like.

The first type is showed in Raman UV-spectra two lines $1538 \mathrm{~cm}^{-1}$ and $1560 \mathrm{~cm}^{-1}$, whereas the second type contributes to the line with maximum at $1560 \mathrm{~cm}^{-1}$. Thermal treatment at $950^{\circ} \mathrm{C}$ results in formation of ribbon-like (chain-like) and PAH-like structures. Increase the temperature up to $1000^{\circ} \mathrm{C}$ limits the type of carbon structure to PAHlike. This is confirmed by disappearing of the line $1538 \mathrm{~cm}^{-1}$. Since the carbon layer placed on free silicide surface seems to be homogeneous ribbon-like and PAH-like structures should be placed rather inside silicide layer than on its surface.

\section{Conclusions}

The application of different excitation wavelengths makes possible to investigate the structural changes of carbon species placed at different locations of SiC-based ohmic contacts.

Increase of $I(D) / I(G)$ ratio in pair $n s c 1 \_3, n s c 1 \_1$ suggests increase of graphitization of the carbon layer with the increase of the temperature used in thermal treatment. Changes of structure of carbon layer are caused not only by the temperature but also by interaction with metallic layer used in the process of ohmic contact formation. The following changes of carbon structures upon thermal treatment are proposed:

(i) nsc1_2-nanographitic structure where $G$ band is probably the combination of "pure $G$ " and $D^{\prime}$ coming from carbon structures with $\mathrm{C}=\mathrm{C}$ bonds; the contribution of the band generated by Ni-GIC structures should be very low or even negligible;

(ii) nsc1_3-graphitic structure with $G$ band consisting of "pure $G$ " with small contribution of $D^{\prime}$ band originated from carbon structures having $\mathrm{C}=\mathrm{C}$ bonds [38]; probably there is also small contribution generated by Ni-GIC species;

(iii) $n s c 1 \_1$-graphitic structure with $G$ band consisting of "pure G" and band generated by Ni-GIC; optionally small addition of $D^{\prime}$ ( $\mathrm{C}=\mathrm{C}$ bonds) is also possible;

(iv) the increase of graphitization between $n s c 1 \_3$ and $n s c 1 \_1$ is accompanied by increase of content of ABA stacking in the mixture of $\mathrm{ABC}$ and $\mathrm{ABA}$ stacking orders.

Large contribution of "Ni-GIC" band in the case of $n s c 1$ 1 1 results from high temperature of thermal treatment $\left(1000^{\circ} \mathrm{C}\right)$ in which the structures Ni-GIC are generated effectively [14]. Negligible intensity of $2 D$ band in the spectrum observed for $n s c 1 \_2$ results probably from the combination of lower limit of the temperature what makes possible observation of $2 \mathrm{D}$ band $\left(800^{\circ} \mathrm{C}\right)$ and short time of application of the temperature [14].

Application of ultraviolet laser line makes possible to observe the signals from thin carbon layer built on the free surface of nickel-silicide film during the process of annealing and the from nanocrystalline species placed in the silicide film. The analysis of the UV-Raman spectra makes possible to derive information about details of the structure of carbon layer placed on the free surface of nickel silicide. The UV-Raman spectrum consist of the $G$ band and narrow lines assigned to ribbon- (chain-) like and PAH-like carbon structures. These structures are placed inside silicide layer than on its free surface. Increase of the temperature up to $1000^{\circ} \mathrm{C}$ removes the trace of chain-like structures from the spectrum.

Small changes between experimental data and the sum of fitted profiles appear in autocorrelation function. These discrepancies suggest that the model used in this paper cannot described all features of carbon structures in ohmic 
contacts. Discussion of the details not included in the presented model will be the subject of subsequent paper.

\section{Acknowledgment}

The research was partially supported by the European Union within European Regional Development Fund, through grant Innovative Economy (POIG.01.03.01-00159/08 "InTechFun").

\section{References}

[1] I. P. Nikitina, K. V. Vassilevski, N. G. Wright, A. B. Horsfall, A. G. O'Neill, and C. M. Johnson, "Formation and role of graphite and nickel silicide in nickel based ohmic contacts to n -type silicon carbide," Journal of Applied Physics, vol. 97, no. 8, Article ID 083709, pp. 1-7, 2005.

[2] H. Matsunami, "Current SiC technology for power electronic devices beyond Si," Microelectronic Engineering, vol. 83, no. 1, pp. 2-4, 2006.

[3] J. Crofton, P. G. McMullin, J. R. Williams, and M. J. Bozack, "High-temperature ohmic contact to n-type $6 \mathrm{H}-\mathrm{SiC}$ using nickel," Journal of Applied Physics, vol. 77, no. 3, pp. 13171319, 1995.

[4] M. G. Rastegaeva, A. N. Andreev, A. A. Petrov, A. I. Babanin, M. A. Yagovkina, and I. P. Nikitina, "The influence of temperature treatment on the formation of Ni-based Schottky diodes and ohmic contacts to n-6H-SiC," Materials Science and Engineering B, vol. 46, no. 1-3, pp. 254-258, 1997.

[5] W. Lu, W. C. Mitchel, C. A. Thornton, G. R. Landis, and W. E. Collins, "Carbon structural transitions and ohmic contacts on 4H-SiC," Journal of Electronic Materials, vol. 32, no. 5, pp. 426-431, 2003.

[6] A. Bächli, M.-A. Nicolet, L. Baud, C. Jaussaud, and R. Madar, "Nickel film on (001) SiC: thermally induced reactions," Materials Science and Engineering B, vol. B56, no. 1, pp. 1123, 1998.

[7] B. Barda, P. Macháč, S. Cichoň et al., "Origin of ohmic behavior in $\mathrm{Ni}, \mathrm{Ni}_{2} \mathrm{Si}$ and $\mathrm{Pd}$ contacts on n-type SiC," Applied Surface Science, vol. 257, no. 2, pp. 414-422, 2010.

[8] M. C. Cheynet and R. Pantel, "Dielectric and optical properties of nanometric nickel silicides from valence electrons energy-loss spectroscopy experiments," Micron, vol. 37, no. 5, pp. 377-384, 2006.

[9] M. Tinani, A. Mueller, Y. Gao, E. A. Irene, Y. Z. Hu, and S. P. Tay, "In situ real-time studies of nickel silicide phase formation," Journal of Vacuum Science and Technology B, vol. 19, no. 2, pp. 376-383, 2001.

[10] S. Y. Han and J.-L. Lee, "Effect of interfacial reactions on electrical properties of $\mathrm{Ni}$ contacts on lightly doped n-type 4H-SiC," Journal of the Electrochemical Society, vol. 149, no. 3, pp. G189-G193, 2002.

[11] Z. Zhang, J. Teng, W. X. Yuan, F. F. Zhang, and G. H. Chen, "Kinetic study of interfacial solid state reactions in the Ni/4HSiC contact," Applied Surface Science, vol. 255, no. 15, pp. 6939-6944, 2009.

[12] L. Calcagno, A. Ruggiero, F. Roccaforte, and F. La Via, "Effects of annealing temperature on the degree of inhomogeneity of nickel-silicide/SiC Schottky barrier," Journal of Applied Physics, vol. 98, no. 2, Article ID 023713, pp. 1-6, 2005.

[13] F. La Via, F. Roccaforte, V. Raineri et al., "Schottky-ohmic transition in nickel silicide/SiC-4H system: is it really a solved problem?" Microelectronic Engineering, vol. 70, no. 2-4, pp. 519-523, 2003.

[14] W. Lu, W. C. Mitchel, G. R. Landis, T. R. Crenshaw, and W. E. Collins, "Electrical contact behavior of Ni/C60/4H-SiC structures," Journal of Vacuum Science and Technology A, vol. 21, no. 4, pp. 1510-1514, 2003.

[15] A. Kuchuk, V. Kladko, M. Guziewicz et al., "Fabrication and characterization of nickel silicide ohmic contacts to n-type $4 \mathrm{H}$ silicon carbide," Journal of Physics, vol. 100, no. 4, Article ID 042003, 2008.

[16] A. V. Kuchuk, V. P. Kladko, A. Piotrowska, R. Ratajczak, and R. Jakiela, "On the formation of Ni-based ohmic contacts to ntype 4H-SiC," Materials Science Forum, vol. 615-617, pp. 573576, 2009.

[17] Z. Adamus, M. Wzorek, P. Borowicz et al., "Influence of carbon layer on properties of ohmic contacts to n-type $4 \mathrm{H}$ $\mathrm{SiC}$," in Proceedings of the 5th Wide Bandgap MaterialsProgress in Synthesis and Applications and 7th Diamond \& Related Films joned with 2nd International Workshop on Science and Applications of Nanoscale Diamond Materials (WBM '10), Zakopane, Poland, July 2010.

[18] J. C. Burton, L. Sun, F. H. Long, Z. C. Feng, and I. T. Ferguson, "First-and second-order Raman scattering from semi-insulating 4H-SiC," Physical Review B, vol. 59, no. 11, pp. 7282-7284, 1999.

[19] A. C. Ferrari, "Raman spectroscopy of graphene and graphite: disorder, electron-phonon coupling, doping and nonadiabatic effects," Solid State Communications, vol. 143, no. 1-2, pp. 4757, 2007.

[20] P. Borowicz, T. Gutt, T. Małachowski, and M. Latek, "Carbonic inclusions on $\mathrm{SiC} / \mathrm{SiO}_{2}$ interface investigated with raman scattering," Diamond and Related Materials, vol. 20, no. 5-6, pp. 665-674, 2011.

[21] A. C. Ferrari and J. Robertson, "Interpretation of Raman spectra of disordered and amorphous carbon," Physical Review B, vol. 61, no. 20, pp. 14095-14107, 2000.

[22] W. Lu, L. C. Feldman, Y. Song et al., "Graphitic features on SiC surface following oxidation and etching using surface enhanced Raman spectroscopy," Applied Physics Letters, vol. 85, no. 16, pp. 3495-3497, 2004.

[23] A. C. Ferrari, J. C. Meyer, V. Scardaci et al., "Raman spectrum of graphene and graphene layers," Physical Review Letters, vol. 97, no. 18, Article ID 187401, 2006.

[24] A. Das, B. Chakraborty, and A. K. Sood, "Raman spectroscopy of graphene on different substrates and influence of defects," Bulletin of Materials Science, vol. 31, no. 3, pp. 579-584, 2008.

[25] P. Tan, S. Dimovski, and Y. Gogotsi, "Raman scattering of nonplanar graphite: arched edges, polyhedral crystals, whiskers and cones," Philosophical Transactions of the Royal Society A, vol. 362, no. 1824, pp. 2289-2310, 2004.

[26] P. Nemes-Incze, Z. Osváth, K. Kamarás, and L. P. Biró, "Anomalies in thickness measurements of graphene and few layer graphite crystals by tapping mode atomic force microscopy," Carbon, vol. 46, no. 11, pp. 1435-1442, 2008.

[27] D. Yoon, H. Moon, H. Cheong, J. S. Choi, J. A. Choi, and B. H. Park, "Variations in the Raman spectrum as a function of the number of graphene layers," Journal of the Korean Physical Society, vol. 55, no. 3, pp. 1299-1303, 2009.

[28] O. Frank, M. Mohr, J. Maultzsch et al., "Raman 2D-band splitting in graphene: theory and experiment," ACS Nano, vol. 5, no. 3, pp. 2231-2239, 2011.

[29] D. D. L. Chung, "Review: graphite," Journal of Materials Science, vol. 37, no. 8, pp. 1475-1489, 2002. 
[30] J.-H. Wong, B.-R. Wu, and M.-F. Lin, "Electronic properties of rhombohedral graphite," Computer Physics Communications, vol. 182, no. 1, pp. 77-80, 2011.

[31] M. Kim, J. Hwang, V. B. Shields, S. Tiwari, M. G. Spencer, and J.-W. Lee, "SiC surface orientation and Si loss rate effects on epitaxial graphene," Nanoscale Research Letters, vol. 7, article $186,2012$.

[32] C. H. Lui, Z. Li, Z. Chen, P. V. Klimov, L. E. Brus, and T. F. Heinz, "Imaging stacking order in few-layer graphene," Nano Letters, vol. 11, no. 1, pp. 164-169, 2011.

[33] S. Fahy, S. G. Louie, and M. L. Cohen, "Pseudopotential totalenergy study of the transition from rhombohedral graphite to diamond," Physical Review B, vol. 34, no. 2, pp. 1191-1199, 1986.

[34] H. Kagi, I. Tsuchida, M. Wakatsuki et al., "Proper understanding of down-shifted Raman spectra of natural graphite: direct estimation of laser-induced rise in sample temperature," Geochimica et Cosmochimica Acta, vol. 58, no. 16, pp. 35273530, 1994.

[35] A. Krueger, "Chapter 1: carbon-element of many faces," in Carbon Materials and Nanotechnology, Wiley-VCH Verlag $\mathrm{GmbH} \&$ Co. KGaA, Weinheim, Germany, 2010.

[36] C. S. G. Cousins, "Elasticity of carbon allotropes. IV. Rhombohedral graphite: elasticity, zone-center optic modes, and phase transformation using transferred Keating parameters," Physical Review B, vol. 67, no. 2, Article ID 024110, 11 pages, 2003.

[37] W. Norimatsu and M. Kusunoki, "Selective formation of ABCstacked graphene layers on $\mathrm{SiC}(0001)$," Physical Review B, vol. 81, no. 16, Article ID 161410, 2010.

[38] W. Lu, W. C. Mitchel, G. R. Landis, T. R. Crenshaw, and W. E. Collins, "Catalytic graphitization and Ohmic contact formation on 4H-SiC," Journal of Applied Physics, vol. 93, no. 9, pp. 5397-5403, 2003.

[39] A. Cosslett and V. E. Cosslett, "The optical density and thickness of evaporated carbon films," British Journal of Applied Physics, vol. 8, no. 9, article 308, pp. 374-376, 1957.

[40] J. G. Carter, R. H. Huebner, R. N. Hamm, and R. D. Birkhoff, "Optical properties of graphite in the region 1100 to 3000," Physical Review, vol. 137, no. 2, pp. A639-A641, 1965.

[41] M. Bruna and S. Borini, "Optical constants of graphene layers in the visible range," Applied Physics Letters, vol. 94, no. 3, Article ID 031901, 2009.

[42] H.-W. Chen and J.-T. Lue, "Ellipsometry measurements of nickel silicides," Journal of Applied Physics, vol. 59, no. 6, pp. 2165-2167, 1986.

[43] M. Amiotti, A. Borghesi, G. Guizzetti, and F. Nava, "Optical properties of polycrystalline nickel silicides," Physical Review $B$, vol. 42, no. 14, pp. 8939-8946, 1990.

[44] Y. Hu and S. P. Tay, "Spectroscopic ellipsometry investigation of nickel silicide formation by rapid thermal process," Journal of Vacuum Science and Technology A, vol. 16, no. 3, pp. 18201824, 1998.

[45] C. Muthumariappan, "Three-component dust models for interstellar extinction," Journal of Astrophysics and Astronomy, vol. 31, no. 1, pp. 17-29, 2010.

[46] R. K. Rai and S. Rastogi, "The scattering and extinction properties of nanodiamonds," Monthly Notices of the Royal Astronomical Society, vol. 401, no. 4, pp. 2722-2728, 2010.

[47] V. Y. Osipov, A. V. Baranov, V. A. Ermakov et al., "Raman characterization and UV optical absorption studies of surface plasmon resonance in multishell nanographite," Diamond and Related Materials, vol. 20, no. 2, pp. 205-209, 2011.
[48] W. Ren, R. Saito, L. Gao et al., "Edge phonon state of monoand few-layer graphene nanoribbons observed by surface and interference co-enhanced Raman spectroscopy," Physical Review B, vol. 81, no. 3, Article ID 035412, 2010.

[49] F. Mazzamuto, J. Saint-Martin, A. Valentin, C. Chassat, and P. Dollfus, "Edge shape effect on vibrational modes in graphene nanoribbons: a numerical study," Journal of Applied Physics, vol. 109, no. 6, Article ID 064516, 2011.

[50] C. Castiglioni, M. Tommasini, and G. Zerbi, "Raman spectroscopy of polyconjugated molecules and materials: confinement effect in one and two dimensions," Philosophical Transactions of the Royal Society A, vol. 362, no. 1824, pp. 2425-2459, 2004.

[51] S. A. Asher, "Ultraviolet resonance raman spectrometry for detection and speciation of trace polycyclic aromatic hydrocarbons," Analytical Chemistry, vol. 56, no. 4, pp. 720-724, 1984.

[52] C. R. Johnson and S. A. Asher, "A new selective technique for characterization of polycyclic aromatic hydrocarbons in complex samples: UV resonance Raman spectrometry of coal liquids," Analytical Chemistry, vol. 56, no. 12, pp. 2258-2261, 1984.

[53] L. Colangeli, V. Mennella, G. A. Baratta, E. Bussoletti, and G. Strazzula, "Raman and infrared spectra of polycyclic aromatic hydrocarbon molecules of possible astrophysical interest," Astrophysical Journal Letters, vol. 396, no. 1, pp. 369-377, 1992. 

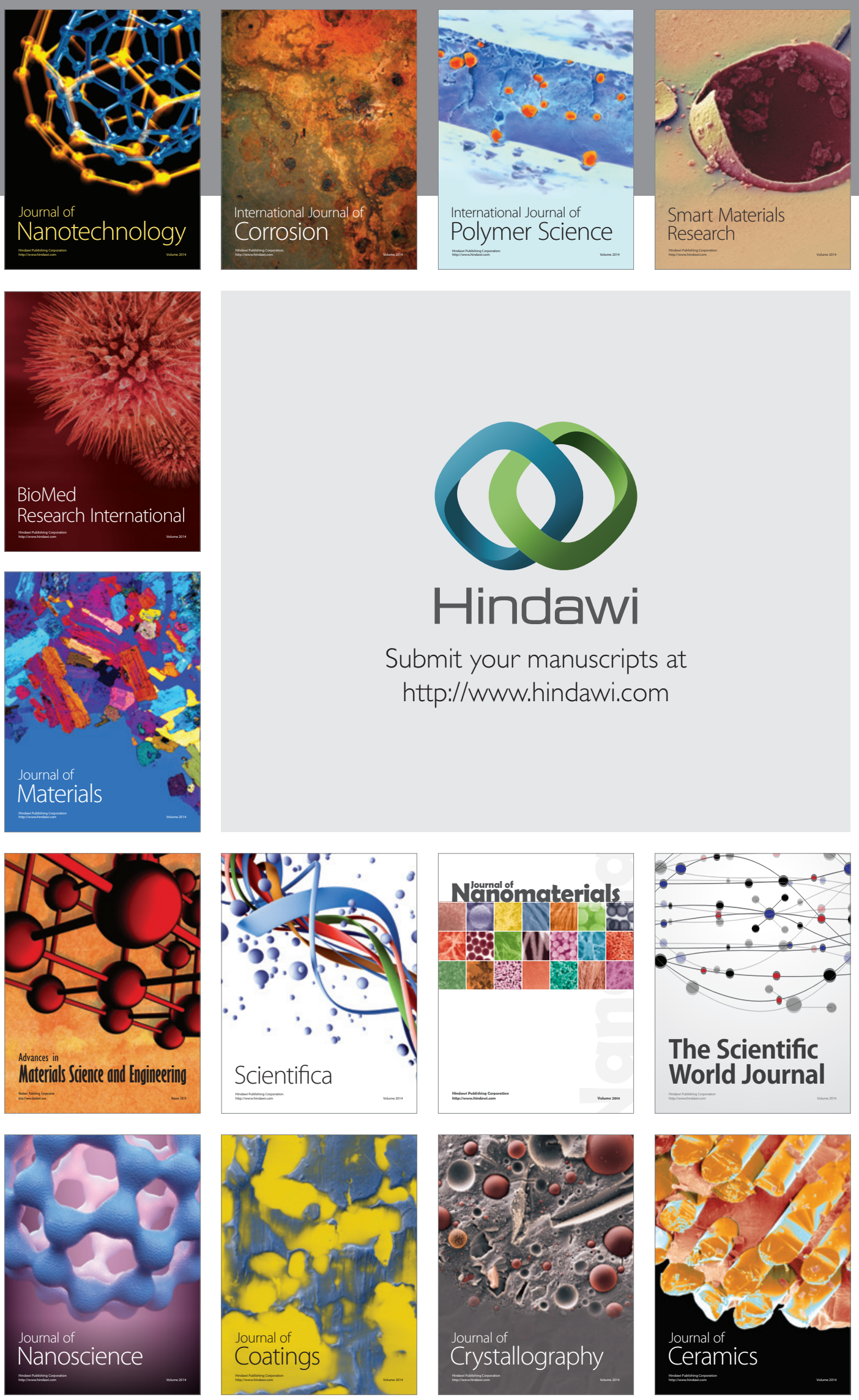

The Scientific World Journal

Submit your manuscripts at

http://www.hindawi.com

\section{World Journal}

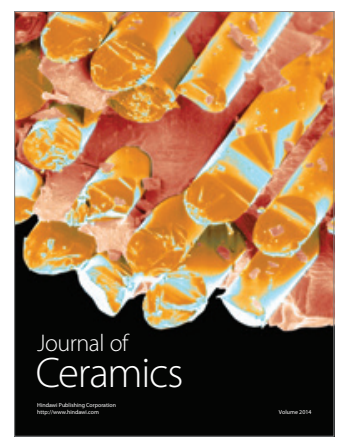

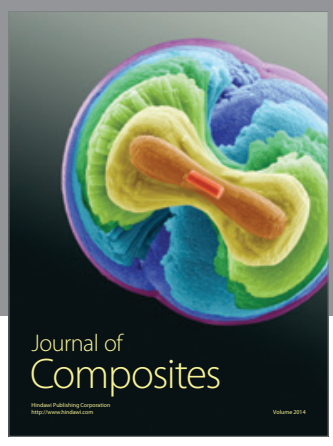
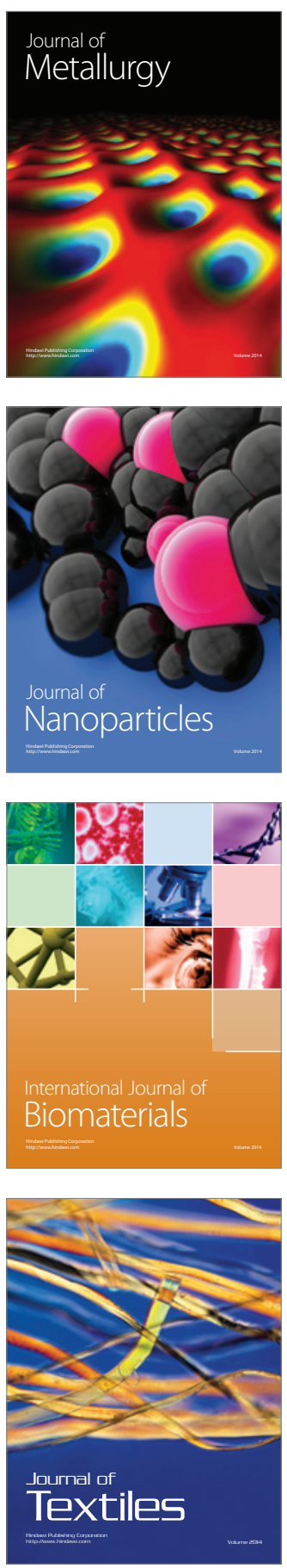